\title{
O LEITOR DE LETRAS EAD: HÁBITOS, SUPORTES E ESTRATÉGIAS
}

\author{
LONDRINA/PR JULHO/2018
}

\author{
Celso Leopoldo Pagnan - Unopar - celso.pagnan@unopar.br \\ Andressa Aparecida Lopes - Unopar - dressalopes@hotmail.com \\ Eliane Provate Queiroz - Unopar - eliprovate@gmail.com \\ Wéllem Aparecida de Freitas Semczuk - Unopar - wellem.semczuk@unopar.br \\ Dayse de Souza Lourenço Simões - Anhanguera - dayse.lourenco1990@gmail.com \\ Adriana Giarola Ferraz Figueiredo - Anhanguera - adriana.figueiredo@kroton.com.br
}

Tipo: Investigação Científica (IC)

Natureza: Descrição de Projeto em Andamento

Categoria: Pesquisa e Avaliação

Setor Educacional: EDUCAÇÃO SUPERIOR

\begin{abstract}
RESUMO
A digitalização de livros começou nos anos 40, mas é no final do século XX que se iniciou a produção de textos digitalizados com mais frequência. Apesar do desenvolvimento de outras tecnologias que servem de suporte à leitura, o impresso continua a circular e a ser bem aceito pelo público leitor. Considerando tal contexto, a presente pesquisa trata dos hábitos e das estratégias de leitura tanto no suporte digital, como no impresso. Entre os objetivos, está o de aferir o nível de percepção dos leitores a respeito de suportes variados de leitura. Como se trata de um estudo qualitativo-exploratório, utilizamos como metodologia a aplicação de um questionário a alunos que cursam graduação a distância em Letras e que tendem a fazer mais leituras em ambientes virtuais, com o objetivo de aferir preferências, bem como capacidade de compreensão textual, de acordo com o suporte utilizado. O instrumento apontado possui questões que visam a compreensão do perfil leitor do aluno de Letras $E a D$, suas preferências no uso de suporte digital ou impresso e, ainda, observar as nuances do processo de leitura em cada suporte, permitindo averiguar se há diferenças no desenvolvimento das competências e habilidades leitoras. Como conclusão prévia, percebeu-se a preferência pelo suporte impresso, uma vez que os alunos, em sua maioria, direcionaram suas respostas ao uso de estratégias de leitura e preferências por materiais e livros impressos. Também foi considerada uma suposta maior capacidade de intelecção nesse mesmo suporte, visto que a familiaridade e a prática mais recorrente de leituras de textos impressos gerou o desenvolvimento das competências de leitura avaliadas pelo presente estudo.
\end{abstract}

Palavras-chave: Leitura; estratégias; suportes; competências; habilidades.

\section{AGRADECIMENTOS}

FUNADESP PELO FINANCIAMENTO DA PESQUISA. 


\section{Introdução}

As Novas Tecnologias de Informação e Comunicação (NTIC) englobam a publicação de e-books ou livros digitais, seja como simples reprodução de textos já impressos, seja como edição específica para o âmbito digital, como exemplo teríamos a literatura digital. Apesar disso, a origem da digitalização de textos impressos data dos anos 1940, quando Bush (1945 [2004]) publica um artigo defendendo o uso da tecnologia como meio de armazenamento de informações. Para tanto, trata do Mémex (Memory Extension), uma espécie de repositório de livros e outros impressos. Na década de 70, por meio do projeto Gutenberg, inicia-se a digitalização de livros e a disponibilização em repositórios com acesso ainda restrito. Apenas em fins dos anos 90, aparecem os primeiros softwares para realização efetiva da leitura digital, por meio de tela plana de cristal líquido e portátil. Epstein (2002) previa que haveria uma nova relação entre autores e editores, por conta do acesso a essas novas tecnologias de publicação. Chartier (2009) também discute as mudanças no papel do indivíduo como leitor na era digital. Além disso, havia o temor, por parte das editoras, de que o livro impresso poderia desaparecer. Segundo dados de pesquisa encomendada pela Câmara Brasileira do Livro, o livro digital (e-book) representou, em 2016, no Brasil, 1,09\% do faturamento das editoras frente à venda de livros físicos. Mesmo nos EUA, cujo mercado livreiro é 25 vezes maior que o do Brasil, verifica-se uma estagnação da publicação de livros digitais e um aumento da edição de livros físicos (NETO, 2018). A explicação pode estar na proximidade maior entre os valores de um formato e outro, mas também na preferência pelo suporte impresso. Apesar do desenvolvimento de outras tecnologias que servem de suporte à leitura, fato é que o impresso (livros, revistas, jornais) continua a circular e a ser bem mais aceito pelo público leitor que e-books. A pesquisa Retratos de Leitura no Brasil (FAILLA, 2016) confirma esse cenário. Entre o público leitor, 10,8\% afirmaram que leram conteúdo digital, sendo que $88 \%$ haviam buscado textos gratuitos, razão pela qual o faturamento do setor é bem menor que o de livros físicos. Nesse contexto, o leitor tem dois suportes de leitura à sua disposição: o impresso e o digital, e diferentes meios para realizar a leitura: livros, jornais, revistas, por exemplo, no caso dos impressos; smartphone, notebook, computador, leitor digital (e-readers), por exemplo, no caso dos textos em formato digital. E, para além dos posicionamentos apocalípticos (MARTIN, 1993) de que a produção do livro impresso teria chegado ao fim, desde a invenção de Gutenberg no século XV, também é certo que a leitura na tela do computador ou outro dispositivo eletrônico modificou o modo de ler (CHARTIER, 2009).

\section{Objetivos}

Considerado tal contexto, queremos apresentar, com o presente artigo, pesquisa 
desenvolvida sobre os hábitos, as práticas e as estratégias de leitura de um grupo específico: os estudantes de graduação em Letras matriculados em um curso de ensino a distância $(\mathrm{EaD})$. A escolha se deve ao fato de o curso de Letras apresentar, entre suas características, o desenvolvimento de competências e de habilidades leitoras. Nesse sentido, presume-se que o estudante de Letras tenha, entre os seus hábitos, o da leitura frequente, seja de obras literárias, seja de textos didáticos e acadêmicos, entre outros. $\mathrm{E}$, no caso específico de serem alunos de curso na modalidade EaD, parte-se do pressuposto de que tais alunos tenham à disposição uma série de materiais digitais, incluindo uma biblioteca digital com todos os livros do referencial teórico das respectivas disciplinas, os quais, conforme Portaria do Ministério de Educação, a n. 11, de 20 de junho de 2017, em seu artigo 11, inciso VI, determina que as bibliografias básicas das disciplinas podem ser disponibilizadas em ambos os formatos: físico ou digital. Nesse sentido, o objetivo do presente trabalho é o de diagnosticar preferências por suporte de leitura de alunos da graduação em Letras $\mathrm{EaD}$, bem como estratégias utilizadas para a apreensão do que se lê nos suportes aludidos.

\section{Referencial teórico}

Com a chegada do século XXI, novas demandas emergiram. A possibilidade de um domínio mais interligado e digital inaugurou um contexto em que o desenvolvimento de novas competências requer, além de criatividade e de inovação, um pensamento crítico, capacidade de resolução de problemas, uma postura colaborativa em relação aos pares, promovendo ações em que os sujeitos envolvidos apresentam mais autonomia e flexibilidade, assumindo a perspectiva de que 0 ato de aprender, de assimilar conhecimentos e de formação passa a ser constante. Nesse cenário, está a questão do acesso à leitura no meio acadêmico que, assim como o próprio contexto, vem sofrendo alterações em função das mudanças ocorridas e das novas probabilidades de interação

e de contato com o conhecimento e as informações que norteiam e constituem uma sociedade.

Em se tratando da leitura, cabe, primeiramente, pensar nessa prática, compreendendo que não se trata de um ato simples, pois diz respeito a uma habilidade que precisa ser aprendida: dentre as muitas habilidades inerentes ao ser humano, ainda que haja a consciência de uma capacidade leitora, não é possível pensar nessa aptidão como algo definido, mas sim que corresponde a uma técnica que precisa ser treinada e reforçada. Dentro da perspectiva sociointeracionista de leitura, há a concepção de que existe uma relação direta entre o leitor e o texto. Por isso, quando diante dessa atividade, e a partir dos conhecimentos acumulados ao longo de sua existência, o sujeito-leitor busca estratégias distintas e suportes possíveis para que a realização desse ato aconteça de 
forma plena e em consonância com os objetivos determinados para essa prática. E, à medida que novas possibilidades de leitura vão surgindo, os modos de organização e de apropriação dos resultados vão se reconfigurando, estabelecendo situações possíveis em contextos viáveis. Diante desse panorama, o leitor torna-se o grande responsável por construir os significados dos textos, destarte, o tipo de interação estabelecido acaba determinando o percurso e, consequentemente, os resultados dessa confluência: "a leitura torna-se vista como um ato construtivo, no qual todos os leitores elaboram sobre as ideias selecionadas de um texto, construindo um significado para ele" (BRÁGGIO, 1992, p. 43), por isso, os suportes acabam se transformando em grandes aliados e corresponsáveis pela efetivação das leituras. Em cada época distinta, o ato de ler requer suportes capazes de atender às necessidades dos leitores naquele enquadramento, quer eles estejam ou não em meio a mudanças e cercados de inovações. Conforme estudos realizados por Coscarelli e Ribeiro (2005), os recursos usados para ler e para escrever sofrem alterações em função das carências do leitor e do mercado, que incorpora uma demanda cada vez mais exigente no que diz respeito a um acesso mais amplo e munido de informações diversas. À vista disso, com o intuito de responder aos anseios dos novos leitores e das exigências do cenário ambientado hodiernamente, o suporte de leitura se reconfigura, advindo das placas de cera, passando pelo pergaminho, pelo papiro, pelo papel, chegando aos meios digitais.

Nesse contexto, ao mesmo tempo em que os novos suportes transformam e mobilizam outras percepções a respeito da prática da leitura, acabam esbarrando em alguns obstáculos, exigindo que o sujeito-leitor traga para o cenário estabelecido o seu conhecimento próprio, o conhecimento de dentro, a fim de encontrar a configuração adequada para manusear o novo recurso, de forma que a leitura aconteça irrestritamente, independentemente da publicação, do suporte e/ou da estratégia escolhida. Contudo, ainda que diante das novas possibilidades ofertadas pelo século XXI, há muitas circunstâncias em que o leitor contemporâneo não consegue se desvincular de hábitos antigos e/ou de práticas consideradas ultrapassadas, e age de forma semelhante à do leitor considerado antigo e tradicional, que faz questão do texto impresso, aquele que alega que um mesmo texto, lido no suporte impresso ou no digital, pode ser absorvido e manipulado de diferentes maneiras. E uma outra questão entra nessa conjuntura, o fato de que, de uma forma ou de outra, o ato de ler e as habilidades leitoras, a despeito dos gêneros textuais, das estratégias selecionadas e dos suportes escolhidos, o sucesso ou o fracasso do desenvolvimento dessa atividade conserva-se como uma incumbência do sujeito-leitor, que realizará esse ato da forma como lhe convier, ou seja, como considerar profícuo e adequado, de acordo com os objetivos da leitura realizada. Mas, conforme observam Coscarelli e Ribeiro (2005), ainda que diante da facilidade da leitura na tela de um computador, por exemplo, o livro de papel suscita 
uma maior funcionalidade se comparado aos suportes digitais, por exemplo, ao se considerar a necessidade de transporte do objeto escolhido de um lado para outro. Sendo assim, o que se pode constatar, é que o comportamento dos leitores brasileiros, perante os suportes de leitura impresso e digital, são recorrências do contexto cultural que os acompanha e das tentativas e recusas de adaptação aos recursos existentes na atualidade. E, em meio ao cenário constituído em presença dessa profusão de possibilidades, algumas questões ainda precisam ser consideradas e analisadas.

\section{Procedimentos metodológicos}

Do ponto de vista metodológico, essa pesquisa é exploratória, pois busca os fatos que contribuem para a ocorrência do fenômeno. Segundo os procedimentos de coleta e as fontes de informação, pode ser definida como bibliográfica e documental. Ainda que o estudo se consolide por meio de resultados quantitativos, gerados por meio de um questionário, a discussão e análise dos dados possui caráter interpretativo, uma vez que se permite a reflexão por meio dos elementos coletados. O corpus foi constituído por dados obtidos por meio de um questionário disponibilizado on-line aos participantes da pesquisa, graduandos em Letras EaD. Foi feita uma ampla divulgação aos graduandos pelos meios oficiais da universidade onde estudam, além do apoio de estudantes que fazem parte do projeto dentro da iniciação científica. Cada aluno tinha, nesse contexto, a mesma possibilidade de responder ou não ao questionário, razão pela qual podemos dizer que o estudo representa uma amostra probabilística aleatória. No caso, 332 graduandos responderam a dezesseis questões. Não apresentaremos resultados de todas as perguntas. Por uma questão de espaço, vamos nos concentrar naquelas que possibilitam uma compreensão de modo a atender os limites dos objetivos determinados no presente artigo. As três primeiras questões tratam do perfil do participante da pesquisa, as demais, dizem respeito aos hábitos de leitura e às estratégias, bem como à utilização de dispositivos para acesso à internet, frequência e finalidade. Salvo quando referidos os dados percentuais, os números apresentados são absolutos. Nem todos os dados apresentados apontam 332, pois foram excluídas respostas negativas como não lê ou lê pouco. Todos esses dados serão agrupados em momento específico.

\section{Apresentação e discussão dos resultados}

Como o principal objetivo do presente estudo é aferir o nível de percepção dos leitores a respeito de suportes variados de leitura, observamos que alguns fatores essenciais a serem investigados seriam: a faixa etária, a preferência entre suportes digitais e impressos e, também, o uso de estratégias de leitura. Nesse sentido, avaliamos que algumas questões apontariam o caminho do leitor graduando em Letras EaD. A primeira 
questão teve como objetivo conhecer a idade do respondente. $O$ objetivo era o de determinar em que geração estaria inserido. No caso, três são as gerações a que podemos fazer referência: as chamadas gerações $X, Y$ e $Z$. Obtivemos as seguintes respostas: Geração X - 56 - Geração Y - 218 - Geração Z - 58. Com base em concepções antropológicas e sociológicas, especialmente após a Segunda Grande Guerra, começou-se a nomear as gerações, conforme características ligadas ao desenvolvimento dos meios de comunicação. Como os Baby Boomers, indivíduos nascidos entre 1946 e 1964, que tinham na televisão o seu canal de comunicação. Em seguida, veio a Geração X, indivíduos nascidos entre 1964 e 1979, época de transmissões ao vivo e a cores pela televisão. Já a Geração $Y$ seria composta por indivíduos nascidos entre 1980 e 2000 e caracterizada pelo acesso às tecnologias de informação e comunicação, pois teriam acompanhado o início da internet quando crianças.

Por fim, haveria, conforme a definição de Prenski (2001, os Nativos Digitais, a Geração Z ou, ainda, Millenials. Indivíduos nascidos a partir de 2001, que foram educados de modo a utilizar-se de dispositivos eletrônicos durante seu processo de formação educacional. Fava (2014) discute o contexto dessa última geração, destacando como atividades cerebrais predominariam sobre as manuais, assim como a virtualidade prevaleceria sobre as práticas tangíveis. Somando as gerações Y e Z, temos 276 respondentes (83\% do total), o que sugere uma relação próxima entre tais indivíduos e uso de tecnologia na educação, particularmente o acesso a materiais digitais para a realização de leitura. Apesar disso, conforme outras respostas indicarão, não é possível estabelecer uma relação causal entre geração e preferência por suporte digital de leitura. Para corroborar as aludidas características das gerações, conforme resposta, $291(87,7 \%)$ dos participantes afirmaram ter acesso à internet em casa, o que facilita a busca por materiais on-line. Apesar de poderem acessar do polo ou do local de trabalho, a maioria prefere utilizar os próprios meios para realizar esse acesso. Para o caso específico da utilização da internet para estudo e pesquisa, 66,9\% afirmaram ficar entre uma e quatro horas por dia. Estabelecendo-se uma relação entre as duas perguntas anteriores, questionamos que dispositivos eletrônicos os participantes teriam à disposição. Apesar de a maioria ter respondido possuir algum dispositivo para acesso a materiais digitais, também afirmaram que nem sempre utilizam tais meios para realizar leituras de livros ou de textos de maneira recorrente.

No gráfico a seguir, distribuímos as respostas entre os que afirmaram ter dispositivos eletrônicos, que poderiam ser utilizados para a prática da leitura, e quantos efetivamente utilizaram tal meio para tal prática. Os números absolutos ultrapassam os 332 participantes, posto que havia a possibilidade de indicar mais de uma resposta. 
Gráfico 1: Utilização de dispositivos eletrônicos para leitura

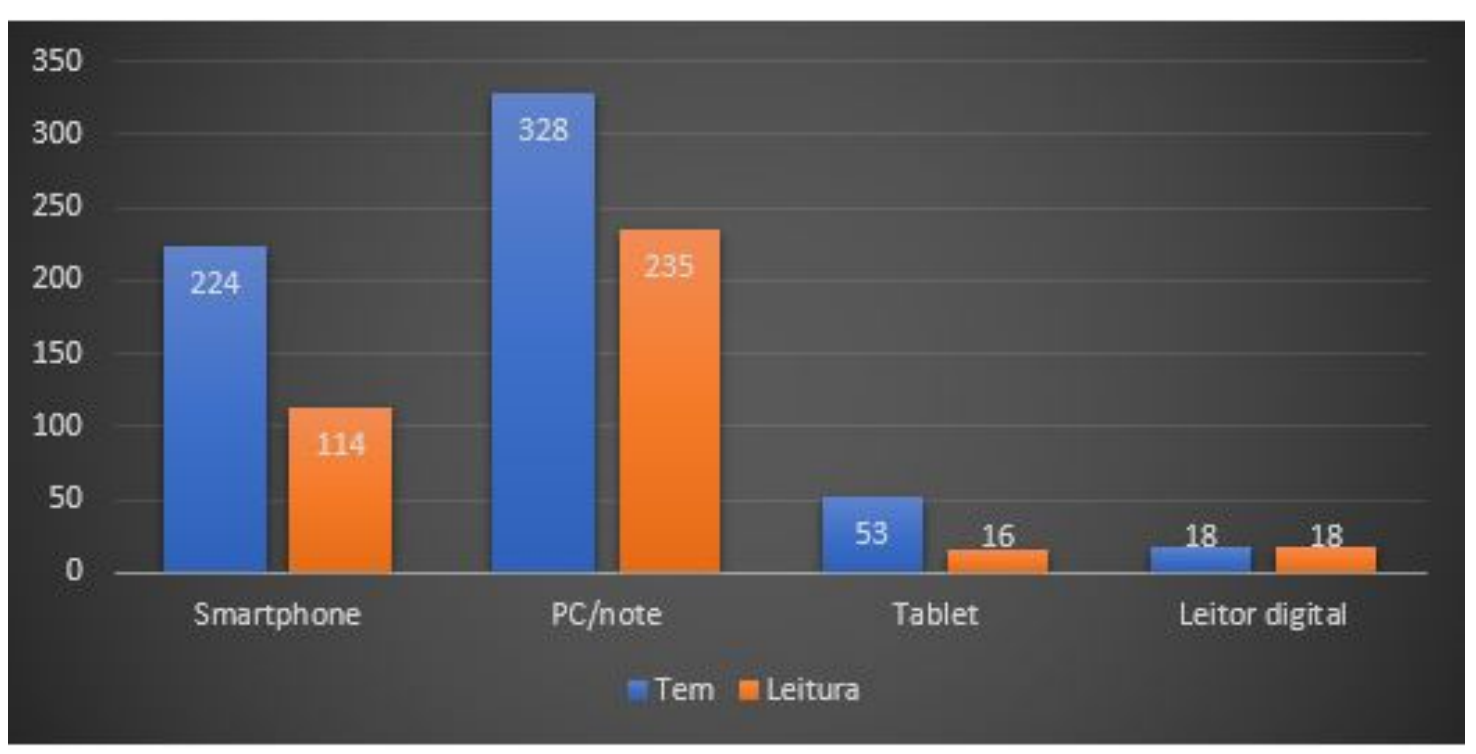

Fonte: os autores

Como se pode observar, a quase totalidade afirmou ter um computador pessoal ou um notebook. Quase 68\% dos participantes afirmaram ter um smartphone. Na pesquisa Retratos de leitura no Brasil, os dados percentuais se diferem apenas nos itens celular e computador: Smartphone 56\%, PC/Notebook 49\%, tablet $18 \%$ e leitor digital $4 \%$. (FAILLA, 2016, p. 263). Apesar da maior mobilidade que este aparelho possibilita, proporcionalmente prefere-se ler em PC/notebook, talvez pelo tamanho da tela. Santaella (2014) divide os leitores em duas categorias maiores, os imersivos e os ubíquos. O primeiro é o leitor do hipertexto, que muda de texto rapidamente; já o ubíquo seria o que lê em qualquer lugar, a qualquer hora, pela facilidade que os dispositivos móveis proporcionam. "O ubíquo deriva do imersivo e brotou tão logo se tornou usuário dos dispositivos móveis os quais Ihe propiciaram a possibilidade de acessar as redes e se comunicar com seus pares e mesmo ímpares de qualquer lugar e em quaisquer momentos" (SANTAELLA, 2014, p. 18). Novamente, segundo as respostas, o graduando do ensino a distância, pertencente ao universo do público pesquisado, prefere dispositivos mais fixos para a realização da leitura. A explicação talvez seja pela necessidade de a leitura, para esse público, fazer sentido e não apenas ser meio de absorção de conteúdo imediato. Por outro lado, a despeito de a maior parte dos participantes pertencerem às gerações $Y$ e $Z$ e que seriam, nesse sentido, conforme a expressão de Prensky (2001), nativos digitais, há uma nítida preferência pelo suporte impresso, tendo em vista que, conforme as respostas dos participantes, possibilitaria uma maior capacidade de intelecção, conforme os dados a serem apresentados a seguir. Na preferência por suporte, tivemos 252 participantes que afirmaram preferir ler em suporte impresso; 42 no digital; e 34 que não tem preferência definida. Baron (2015) 
constata essa mesma preferência, quando afirma que, em pesquisa realizada por ela, a maioria (não cita o percentual) diz preferir ler textos impressos, posto que nesse meio a leitura seria mais prazerosa e facilitaria a compreensão.

Ainda no âmbito das preferências, perguntamos, diante de um texto disponibilizado no formato digital, se o participante preferiria ler nesse suporte ou se imprimiria. Do total, 127 afirmaram sempre imprimir; 118 costumam ler diretamente na tela do dispositivo eletrônico; e 87 que imprimem ocasionalmente. A hipótese para essa preferência, já aludida por Baron (2015), pode ser mais por um hábito arraigado, mesmo entre os participantes mais jovens, que teriam no objeto físico uma concretude que o digital não permite. Mangen; Walgermo; Brønnick (2012) constataram que, em rigor, quanto à compreensão, especialmente considerando a progressão narrativa, não haveria significativas diferenças entre a leitura em um ou em outro suporte. De qualquer modo, perguntamos aos participantes se percebiam diferenças, no âmbito da compreensão, na escolha do suporte de leitura. Indo ao encontro do que responderam para as perguntas anteriores, o impresso ainda tende a ser o preferido. Conforme os participantes, 217 acreditam ter uma melhor compreensão do que leem no suporte impresso; para 82 isso seria indiferente; e 30 acreditam que leem melhor no digital. A afirmação vai ao encontro de alguns testes realizados em escolas norte-americanas na primeira década do presente século. Tais testes "[...] indicam um decréscimo na habilidade de ler e compreender textos, atribuído à perda da capacidade de concentração e de foco continuado que a leitura tradicional demandava. Por outro lado, os defensores da leitura na internet dizem que esta permite que pessoas leiam alguma coisa [...] e cria outras habilidades, como a de combinar informações de múltiplos acessos" (JOBIM, 2009, p. $67)$.

Já o Programa Internacional de Avaliação de Estudantes (PISA), que até 2015 analisou o que chamam de textos fixos (não importa o suporte e sim que se trata de texto estático); os chamados textos dinâmicos (disponíveis em sites ou blogs, por conterem hipertextos) serão alvo de avaliação na prova de 2018, de modo a abordar as habilidades leitoras dos alunos em leitura não sequencial. De qualquer modo, a prova de 2015 foi realizada pelos alunos lendo as questões na tela de um computador. Apesar disso, as questões eram baseadas em textos fixos. Procurou-se uma equivalência de textos a serem lidos em material impresso e no dispositivo eletrônico, isto é, sem a referência a hipertextos. Se tomarmos a média dos estudantes, de 2009 (412), 2012 (410) e 2015 (407), podemos perceber que não se trata de diferença significativa. Houve uma leve queda na média da proficiência dos estudantes brasileiros, cuja explicação não se restringe ao fato de terem feito a prova em computadores. Seria preciso considerar outras variáveis. Ao que parece, a maior compreensão de leitura em um suporte ou 
outro estaria no âmbito do uso correto das estratégias para cada caso. Pesquisas diferentes podem revelar resultados diferentes devido à metodologia, mas também ao público pesquisado. Em rigor, o leitor proficiente, ainda que possa revelar alguma preferência por determinado suporte, tende a revelar semelhante capacidade de intelecção. Desse modo, podemos pressupor que as habilidades leitoras no universo digital não foram bem desenvolvidas, porque faltariam essas mesmas habilidades no âmbito do impresso. Mas também por faltar estratégias específicas para a leitura proficiente em ambientes digitais. Isso se confirma, quando abordamos as estratégias de leitura, e as mais utilizadas são comumente as utilizadas para leitura de textos impressos, como sublinhar (225 respostas); fazer anotações (183); verificar os implícitos (144) e fazer resumo (118). As duas estratégias mais citadas, sublinhar (225) e fazer anotações (183), estão disponíveis, por assim dizer, em ambos os suportes. Programas utilizados para se ler Portable Document Format (PDF) permitem que o leitor crie notas ou que destaque trechos significativos. Quanto à verificação dos implícitos ou hábito de se fazer resumo, isso pressupõe estratégias cognitivas e interacionistas de leitura, isto é, o leitor procura dialogar com o texto, estabelecendo uma interação dialógica entre o que lê e o texto em si, de modo a colaborar para a construção do significado.

\section{Considerações Finais}

A presente pesquisa tratou dos hábitos de leitura de graduandos em Letras de um curso EaD. A escolha desse público se deu pela pressuposição de que, a maior parte, devido às características do profissional a ser formado na área, teria hábitos constantes de leitura. Isso se confirmou. A cada pergunta, colocamos como alternativa opções negativas sobre o hábito de ler. Frente ao universo de participantes, houve poucas respostas negativas, como ler menos de uma vez por semana (20 respostas), ou não utilizar qualquer estratégia de leitura (8), mas que, certamente, não deve condizer totalmente com a verdade, afinal, sempre utilizamos uma ou outra, mesmo que de modo inconsciente. Treze participantes afirmaram que não costumam ler em suporte digital e outros onze afirmam não ler texto impresso. Outra pressuposição é que, pela particularidade do curso, haveria uma predisposição maior para a prática de leitura por meio de dispositivos eletrônicos. Não foi o que a pesquisa apontou. Como a pesquisa é fundamentada em questionário, com base em amostra probabilística aleatória, parte-se do princípio de que as respostas sejam verdadeiras, sugerindo, portanto, tendências. No entanto, é possível refletir sobre as respostas e supor que se trata de uma escolha que toma por referência hábitos arraigados. Por outro lado, o perfil dos respondentes, pertencentes, em sua maior parte, às gerações $Y$ e $Z$, leva a supor que o uso das NTIC seria mais comum que a utilização do suporte mais antigo. Em síntese, talvez ainda tenhamos de passar por um processo de aprendizagem para realizar a leitura em 
ambientes e suportes digitais com maior proveito cognitivo.

\section{Referências}

BRÁGGIO, Sílvia Lúcia Bigonjal. Leitura e alfabetização: da concepção mecanicista à sociolinguística. Porto Alegre: Artes Médicas, 1992.

CÂMARA Brasileira do Livro. Pesquisa. Realizada por Fundação Instituto de Pesquisas econômicas. 2016. Disponível em: Acesso em: 2 maio 2017.

CHARTIER, Roger. A aventura do livro: do leitor ao navegador. São Paulo: Imprensa Oficial do Estado de São Paulo: UNESP, 2009.

COSCARELLI, Carla Viana; RIBEIRO, Ana Elisa. Letramento Digital: Aspectos sociais e possibilidades pedagógicas. Belo Horizonte: Ceale, Autêntica, 2005, p. 125-150.

EPSTEIN, Jason. O Negócio do Livro: passado, presente e futuro do mercado editorial (Tradução: Zaida Maldonado). Rio de Janeiro: Record, 2002.

FAILLA, Zoara (org.) Retratos da leitura no Brasil. 4. Rio de Janeiro: Sextante, 2016.

MARTIN, H.J. Le message écrit: la réception. Conferência dada na Académie des Sciences Morales et Politiques. Paris 15 de março de 1993.

NETO, Leonardo. Nos EUA, livros impressos continuam subindo enquanto que os digitais caem. Publishnews. 19 fev. 2018. Disponível em: Acesso em: 4 maio 2018.

MANGEN, A.; WALGERMO, B.R.; BRØNNICK, K. Reading linear texts on paper versus computer screen: Effects on reading Comprehension. Disponível em: $<$ http://www.sciencedirect.com/science/article/pii/S0883035512001127> Acesso em: 2 maio 2018.

PRENSKY, M.: Digital Natives Digital Immigrants. In: PRENSKY, Marc. On the Horizon. NCB University Press, Vol. 9 No. 5, October, 2001.

SANTAELLA, Lucia. A aprendizagem ubíqua na educação aberta. Revista Tempos e Espaços em Educação. Vol. 7, N. 14, set/dez 2014. 